\title{
Increasing the Transparency of Animal Experimentation: An Australian Perspective
}

\author{
Monika Merkes \\ President, Humane Research Australia; Honorary Associate, La Trobe \\ University \\ m.merkes@latrobe.edu.au
}

Rob Buttrose

Humane Research Australia

rob-buttrose@outlook.com

\section{Introduction}

Transparency involves communicating meaningful information (e.g. data or details of decision-making processes) to audiences, openly and honestly, with the intention of informing, enabling understanding and meeting responsibilities of accountability.

YEATES and REED, 2015, p. 504

It has been argued that citizen stakeholders would be well served by greater transparency. The Transparency Register of the European Union (EU) (2016), for example, states that "Transparency is [...] a key part of encouraging European citizens to participate more actively in the democratic life of the EU". But why is transparency in non-human animal (hereinafter referred to as animal) research desirable, or indeed vital? Hadley (2012) argues that the public finance much animal research but do not know what impact their taxes and donations have on animals. Furthermore, he suggests that, since "people enjoy the benefits of animal research when they consume pharmaceuticals or undergo surgical procedures that prolong or improve the quality of their lives, it seems reasonable to inform them of the costs to animals for which their consumer choices are to some extent causally responsible" (Hadley, 2012, p. 105). Good governance is another reason for transparency in animal research. Thus, McLeod and Hobson-West suggest that one of the key themes "in the science governance literature is the linking of transparency and public trust (or mistrust)" (2015, p. 792). Varga et al. concur that "more transparency will increase

(C) MONIKA MERKES AND ROB BUTTROSE, 2019 | DOI:10.1163/9789004391192_010 
public confidence in the appropriate conduct and regulation of animal research and therefore help to maintain public acceptance" (2010, p. 500).

Some in the research community have supported increased transparency to improve the public's understanding of animal research and boost its acceptability. "Underpinning this idea is a belief that animal rights advocates use public ignorance to benefit their cause. Thus, the only way to counter the damage done to the animal research community's public image is to increase the lay community's understanding of research practices" (O'Sullivan, 2006, p. 6). In contrast, animal advocates emphasize the importance of public debate and awareness of the reality of research animals to improve animal welfare and to work towards an end of animal experimentation. In general, animal advocates are confident that the more the public knows about animal research, the less it will be willing to sanction it. In their public pronouncements, then, both researchers and animal advocates consider increased transparency to be in their own best interest (O'Sullivan, 2006). The critical issue is what information should be available and given focus.

Most people know nothing or little about animal research. For example, an opinion poll, commissioned by Humane Research Australia (HRA) in 2013, found that $43 \%$ of Australians were not aware that animals are used in experimental research in Australia (Humane Research Australia, 2016a). Few people who live in countries where animal experiments occur know much detail about the numbers and species of animals used, the types of procedures they endure, or the pain and suffering involved (Hadley, 2012), as well as the ineffectiveness of using animals as models for humans. The public is interested, however, in these details. A public consultation in the United Kingdom-to which animal activists and scientists were not invited-found public support for openness and interest in a wide range of key information (Ipsos MORI, 2013). Information of interest includes, for example, details about animal use (e.g., organizations that use animals, numbers and percentages of animal species used, severity of procedures, how animals are killed, and whether there are non-animal alternatives); information about genetically altered animals; outcomes for animals, such as levels of suffering, with examples and images of typical procedures; more information about alternatives to animal use; and reports on finished projects from an animal welfare point of view. Furthermore, people asserted the animal research sector "should subject itself to external scrutiny by those who have an interest in the animals' welfare, rather than by those who have a vested financial or scientific interest in the research being carried out" (Ipsos MORI, 2013, p. 37). A later Ipsos MORI poll found that $42 \%$ of respondents perceive UK organizations that use animals for research as "secretive" (Clemence and Leaman, 2016, p. 2). 
In countries, such as Australia and those of the European Union (EU), researchers collect data of interest to the public, but there are differences, as we explore below, in the regulations governing disclosure and the format of the information. Over the past decade, some animal research institutions have, seemingly, made efforts to promote their work and provided information beyond what is legally required. Examples include, the Concordat on Openness on Animal Research (Understanding Animal Research, n.d.), a group of more than 100 universities, charities, commercial companies, research councils, umbrella bodies, and learned societies in the $\mathrm{U} \mathrm{K}$ that have agreed to be more open about their use of animals in research; and the Basel Declaration, signed by scientists and institutions who aspire to speak openly about their work with the public (Basel Declaration, 2011). The Basel Declaration is, however, in large part merely an agreement to abide by legal requirements already governing animal research.

Governments and regulators may also attempt to be more open. For example, in 2015, the UK Government expressed a commitment to increase openness and transparency in animal research with the intention of "giving the public new tools and opportunities to understand how and why such research is carried out and to scrutinize the steps being taken to minimize suffering and find alternatives" (Home Office Department for Business Innovation and Skills and Department of Health, 2015, p. 7). It has been obvious, however, that such openness is selective and "can be viewed as grease in the apparatus of animal experimentation, as a unifying ingredient that permits maintenance of status quo in human/animal relations and preserves existing institutional public/science relations" (Holmberg and Ideland, 2012, p. 354). Holmberg and Ideland observed that the public debate on animal experimentation is constrained by selective openness and by the motivation to enlighten an uninformed public, hoping to gain public acceptance. Thus, they argue, selective openness permits the maintenance of the status quo and preserves existing institutional relations between scientists and the public.

Funding for biomedical research in Australia is substantial. In 2017, the National Health and Medical Research Council (NHMRC) committed more than AUD $\$ 877$ million to fund health and medical research (in 2016, more than AUD $\$ 828$ million; in 2015, more than AUD $\$ 896$; and in 2014, more than AUD $\$ 780$ million) (NHMRC, 2018). Australian biomedical research is generally regarded as being of high quality, and it uses many animals. According to information provided by NHMRC staff to HRA, 34\% of grant applications in 2015 indicated the use of animals in their research (personal communication, March 2016). In this chapter, we detail attempts by Australia's largest and most active 
anti-vivisection organization, Humane Research Australia (HRA), to test the professions of openness and obtain more information than is publicly available about animal research. HRA is a non-profit organization that challenges the use of animal experiments and promotes more humane and scientifically valid non-animal methods of research. Both authors are on HRA's management committee. HRA is abolitionist in aim, but one of its medium-term strategies is to raise public awareness and highlight the failures of the regulatory system, particularly those of animal ethics committees and state animal welfare laws.

In this chapter, we contrast the Australian situation with the EU system, discuss impediments to disclosure, and advocate that reform of animal research regulations in Australia and the EU be focused around these impediments. Furthermore, we provide some suggestions on how reform could be achieved. We argue that such reform and our advocacy will lead to increased scrutiny, which in turn will lead to greater reduction and replacement of animals used in research.

\section{Transparency in Australia}

Animal research in Australia is guided by the NHM RC's Australian Code for the Care and Use of Animals for Scientific Purposes (the Code): "The purpose of the Code is to promote the ethical, humane and responsible care and use of animals for scientific purposes. The Code provides an ethical framework and governing principles to guide decisions and actions of all those involved in the care and use of animals for scientific purposes. The Code details the responsibilities of investigators, animal carers, institutions and animal ethics committees (AECs), and all people involved in the care and use of animals, and describes processes for accountability" (NHMRC, 2013, p. 1).

Under the Australian federal system, responsibility for animal welfare is delegated to the states, and all states and territories have incorporated the Code into state legislation. While being part of a self-regulatory system, the Code "receives its regulatory power by adoption under the state's delegated animal welfare legislation, or through administrative controls, for example referral to it in licenses issued to research establishments" (Whittaker, 2014, p. 3). In the absence of federal regulatory power, statutory provisions relating to animals used in research vary between jurisdictions. Central to the Code is the commitment to minimize harm, pain, and distress to animals used in the laboratory and other research or teaching situations, and "balancing whether the potential effects on the wellbeing of the animals involved is justified by the 
potential benefits to humans, animals or the environment" (NHMRC, p. 1). Balancing is to be achieved by applying the ${ }_{3}$ Rs: replacement (not using animals where possible); reduction (reducing the number of animals used); and refinement (minimizing negative impact on the animals). However, many terms used in the Code are imprecise or undefined (e.g., regularly, suitable, adequate, necessary). While the Code requires that research activities must balance whether the potential effects on the well-being of the animals involved are justified by the potential benefits to humans, there is no explicit requirement that the potential benefits for humans outweigh certain impacts on animals, such as pain and death. This leaves the balancing wide open to interpretation.

Animal ethics committees (AECs) are essential to the implementation of the Code. All projects and activities that involve the care and use of animals for scientific purposes are subject to ethical review, approval, and monitoring by an AEC. AECs are composed of a chairperson, a veterinarian, a scientist or teacher, with experience relevant to the institution's activities, a person with a background and commitment to animal welfare, and an independent community member. Additional members can be appointed, but animal welfare representatives and community members must, together, represent at least one-third of the AEC membership.

\subsection{Animal Use Data}

Unlike many other countries, Australia does not maintain a national collection of animal use data. Moreover, collection and reporting methods vary between states/territories, and delays in making data available can extend up to five years (personal communication, HRA staff, March 2017). Some states and territories do not collect relevant data at all. It is ironic that the only national statistics in Australia are those collated and published by HRA, an anti-vivisectionist organization. HRA gathers annual statistics from the states/territories and makes them available on its website (Humane Research Australia, 2016b). The latest available statistics, at the time of writing, are from 2016 and are only from four states. On the basis of the most recent and previous statistics, HRA estimates that the total number of animals used in Australia in 2016 was over 9 million (Humane Research Australia, 2016c). The information from the states is presented in different formats, using different categories. Not all states collect all of the data recommended by the Code. For example, New South Wales does not collect data from schools, and in Western Australia reporting on research using fish and cephalopods is not mandatory. Due to the discrepancies in data, it is impossible to paint an accurate picture of animal use in research and teaching in Australia. HRA's estimates are approximate, in part based on averages, and conservative. 


\subsection{HRA Attempts to Obtain Animal Research Information}

As an animal advocacy organization, HRA has made systematic attempts to break through the confusing and varied policies on transparency across the Australian states. We make requests to relevant institutions and often follow up with a Freedom of Information (FOI) application, if unsuccessful. Under Australian Commonwealth and state law, government agencies cannot refuse requests by the public for access to information they hold, unless there are good grounds, such as national security or the privacy of individuals, for not doing so. In general, there is a presumption that the public has a right to information. As a result, an FOI request can be a powerful tool. Examples of information disclosed recently include details of sexual assaults at Australian universities, incident logs from Australia's offshore detention centers, and statistics relating to arrests at Melbourne airport concerning prohibited items. Agencies are not always cooperative, however, as we detail in the next section.

HRA asks for documents and reports and information about incidents in laboratories and associated facilities that come to our attention, such as details on the unexpected deaths of two non-human primates at a breeding colony in New South Wales in 2015. In some cases, HRA has asked for a review from the state FO Commissioner. Generally, because our efforts are more targeted, informed, and sustained, HRA finds more information than is available in the public domain or that individuals could expect to discover. Many requests for information, however, are refused. Agencies give a variety of reasons, many of which are not convincing, and skirt their responsibility, outlined in the previous paragraph, to be transparent; reasons include, for example, that the agency does not hold the information nor does it know who holds it, retrieving the information would be an unwarranted use of resources, or "it is generally understood that this information will not become public" (personal communication, May 2014).

\subsection{Animal Ethics Committee (AEC) Material}

Like many animal advocates (e.g., O'Sullivan, 2006; Varga et al., 2010; Whittaker, 2014), at HRA we believe available information about animal research should enable members of the public to make judgments about whether the use of animals is justified given what was done to them, the benefits realized, and the lack of alternatives to realize the benefits. Uncontroversially, we view this as THE ethical question to ask from a utilitarian perspective, the standard ethical framework in which judgments about human use of animals are usually made.

HRA's primary target, then, is to find information about particular research projects. To enable a judgment about justification, we view the following details as essential: 
1. The project proposal

2. Purpose and predicted benefits

3. Detailed consideration of non-animal alternatives

4. Animal species and numbers

5. Impacts on the animals

6. Fate of the animals once the project has been completed

7. Realized benefits of the research.

With the exception of realized benefits of the research, all details about a project are already documented. In Australia, the Code requires they be part of the application process. Although the Code allows some flexibility of implementation, as it does in many matters, most AEC project forms that we were able to access strictly conform to these requirements (e.g., University of Melbourne Office, n.d.). All details then, which in our view are sufficient to make a judgment about justification at the project level, should already exist in various records, reports, and databases. However, we cannot verify whether this collection and compilation of information is always carried out and how well it is done. We cannot verify compliance because these details are not publicly accessible.

Other information we view as important for judging the current level and nature of animal experimentation in Australia is also unavailable for public viewing. These data include summary statistics collected by the states and territories from the AECs ("animal use returns"); and efforts by institutions and other license holders to reduce animal use, as described in the annual AEC reports. HRA's success rate in gaining access to AEC documents, by directly requesting them, has been disappointing. For example, we contacted all major Australian universities to ask for their annual AEC reports for a range of years. Only in one case did we receive a positive response. In all other cases, we either did not receive a response or the request was refused on the grounds that it was not the practice of the institution concerned to make this material public. Requests for project applications (even redacted versions), progress reports, and final reports were also not granted.

\section{$2.4 \quad$ License Holder Names}

In 2014, an FOI request was pursued on appeal to the FOI Commissioner in Victoria. The request was for the names of the license holders, the institutions, and other bodies that are licensed to undertake animal research. The request, by one of the authors on behalf of HRA, did not ask for the names of individuals; and this was made explicit in the application. A typical license holder is not a person, but an institution, such as a university or part of a university. HRA has an interest in these details, both to gauge the number and range 
(e.g., public versus private) of animal research in the state and to guide our search for publications, which is the most definitive way in which we can establish that particular research has taken place in Australian institutions. We are aware of many of the license holders already, both because of publications found independently and the nature of the institutions, such as universities and research hospitals. Some of these institutions put information about license holders or their AECs on a website. As HRA stressed in its original request and in subsequent appeals, we were not interested in nor seeking to identify any individuals, whether they be institution administrative staff or researchers.

Although our request for the license holder names seems uncontroversial, it was refused. In its decision, the department cited four sections in the Freedom of Information Act (1982, last amended 2017), which can be applied to exempt information sharing. Two sections relate to confidential business and commercial details; one to the disclosure of "the personal affairs of [...] person[s]"; and the last to the case where disclosure of a document would or would, likely, "endanger the lives or physical safety of persons [...] who have provided confidential information in relation to the enforcement or administration of the law" (Freedom of Information Act, 1982, last amended 2017, $31(1)(e))$. Somewhat surprisingly, on appealing this decision, the FOI Commissioner dismissed each ground for exemption except the last. Thus, of all the reasons given by the department's FOI officer for not making the license holder names public, only the exemption relating to the physical security of individuals was upheld. Such inconsistency in the treatment of requests for information about animal research from Australian regulators is fairly typical in HRA's experience.

In its submission to the FOI Commissioner, the department's evidence that revealing license holders would endanger individuals, consisted solely of the claim that, in a previous FOI request, two license holders had concerns about being identified, as they had been the target of threats, disruptive action, and property damage from protesters in the past (FOI Commissioner, personal communication, September 2014). HRA does not find it credible that the security concerns of two out of all license holders in Victoria (HRA estimates this number to be between 50 and 100) were enough to reject the request. We were not provided with any evidence of the claims made by the licensees, and our attempts to verify the incidents with a further FOI request to the Australian Federal Police were not successful. Violence against animal laboratories and infiltrations are rare and have decreased markedly over the past 20 years.

In another sign of inconsistent regulation and policy, this time at the state level, license holder information from other states in Australia has been made available to us on request. In Queensland, the register of scientific animal use 
(Queensland Government Department of Agriculture and Fisheries, 2014) can, by law, be inspected by any member of the public. License information is even more accessible in Tasmania, via a website (Tasmanian Government, Department of Primary Industries Parks Water and Environment, 2017). These differences between states call into question the Victorian FOI Commissioner's ruling. If security and risk to individuals are not an issue in other states, why would they be a problem peculiar to Victoria? In 2015, a further FOI application was submitted (after responsibility had been transferred to a different department), asking again for the license holder names. The request was refused on the same grounds, including those previously disallowed by the FOI Commissioner.

Transparency in the European Union

\subsection{Concordat on Animal Research}

The Concordat on Openness on Animal Research is an initiative that aims to make animal research more transparent in the UK. It came into effect in 2014. More than 100 signatories on the Concordat have made a commitment to:

- Being clear about when, how, and why they use animals in research

- Enhancing communications with the media and the public about their research using animals

- Being proactive in providing opportunities for the public to find out about research using animals

- Reporting on progress annually and sharing their experiences.

The efforts of the parties to meet their commitments vary widely. Some only have a web page describing the institution's efforts in implementing the ${ }_{3} \mathrm{Rs}$, ethical reviews, and animal welfare standards. Others provide detailed examples of animal research, such as case studies. Some signatories have published the minutes of the Animal Welfare and Ethical Review Body (AWERB) meetings on their websites. The 2017 Concordat Annual Report (Williams, 2017) makes particular mention of these new efforts at openness. The minutes we accessed were, however, all in a redacted and abbreviated form and, crucially, contained little evidence or detail of ethical review (e.g., University of Nottingham, n.d.). Individual protocol information is lacking, making it difficult to determine what will be done to the animals. The University of Cambridge AWERB minutes, for example, routinely redact the title of project for new and existing licenses (University of Cambridge, 2018). Signatories to the Concordat tend to stress the benefits of animal research, generally, and the importance and necessity of their own researchers' work in particular; while downplaying the 
pain and suffering caused to animals and the number of animal deaths. Unsuccessful research and negative findings are not reported (Pound and Blaug, 2016).

The Ipsos MORI poll finding, mentioned above, that respondents equated transparency of the animal research sector with its willingness to subject itself to external scrutiny by those interested in animal welfare, was not honored in the Concordat (Pound and Blaug, 2016). This is despite the fact that the poll was commissioned by UAR, the group responsible for establishing the Concordat. These omissions are significant; but the Concordat, nonetheless, seems a step in the right direction that Australia could follow. There is always the chance that there could be more balanced disclosure over time, not least because of pressure from animal advocates. In Australia, we have nothing even remotely similar to the Concordat. Rather than promoting their animal research, institutions are much more interested in concealing it. Given our previous experience with innocuous requests, such as the names of license holders described above, we expect there would be resistance on the grounds of security. The UK experience, however, suggests this fear would be unfounded: "When the Concordat was developed there was considerable concern cited about the risks of openness and a fear that transparency would bring researchers into physical danger. The information provided by signatory institutions about their communications activities since May 2014 indicates clearly that this has not been the case" (Williams, 2015, p. 4).

\subsection{Non-technical Summaries (NTS) and Retrospective Assessments (RAs)}

Non-technical summaries (NTS) of animal research are mandated by the EU Directive 2010/63/EU (European Parliament, 2010, Article 43). NTs provide information on the objectives of a project; predicted harm and benefits and the number and types of animals to be used; and a demonstration of compliance with the requirement of replacement, reduction, and refinement. NTS are anonymous and do not contain the names and addresses of the user and its personnel. EU Member States are required to publish the summaries, including any updates. In the UK, the Home Office has published summaries on its website since 2014 .

While the summaries include answers to the crucial questions about any animal research project, which enable an ethical assessment of harms and benefits to be considered, there is variety in the detail and quality of the information provided. There are, however, some uniformities and generic responses, which are unsatisfactory. In response to the question why animals need to be used and non-animal methods cannot, project applicants routinely claim 
that they must develop in vivo models because in vitro models are inadequate to model the disease, condition, or cell interactions being investigated. With respect to refinement, researchers typically respond with a statement that the methods and procedures are designed to minimize suffering. Invariably, there is an additional statement that anesthesia will be given where required, and that the animals will be constantly monitored for signs of pain and distress and killed if these reach moderate severity. Applicants often comment that achievement of the aims of the research limits the minimization of suffering possible.

Directive 2010/63/EU requires retrospective assessments (RAs) of projects using non-human primates and projects involving procedures classified as $s e-$ vere. EU Member States may require RAs for additional types of projects as well. However, including an RA of a completed project in the NTS is optional. We found no mention of an RA in any of the NTS we examined (including summaries of projects using non-human primates and involving severe procedures). In the UK, RAs of projects approved by the Home Office are currently under review and will be published in due course. The British Animals in Science Regulation Unit also plans for NTs to be updated with RAs (personal communications of Kathrin Herrmann with the Animals in Science Regulation Unit, June 2017). In Australia, we view an initiative like the provision of NTs, with all its deficiencies, as worthwhile. The categories of information provided are similar to those we would like to see publicly available in Australia, notwithstanding, the lack of clarity regarding the extent of retrospective assessment at this time.

There are, however, several obstacles to the implementation of NTS and RAS in Australia, which do not apply in the EU. First, in the EU, research animal legislation is mostly national rather than state based. To provide summaries of all animal research projects in Australia would require the agreement and cooperation of all state departments, an objective never easily achieved. Second, Australian state government departments do not license projects, institutions do. Investigators are required by the Code to be "competent" in the care and use of animals, but the Code does not state explicitly who makes that judgment. The AECs approve or license projects. Yet, some tentative moves have been made in this direction. As early as 2003, the Australian and New Zealand Council for the Care of Animals in Research and Teaching (2007, pp. 5-6) drafted a proposal for, what it termed, lay summaries of animal research to be published. The format for the summaries was as follows:

- Provide the context of the study by way of a brief background

- Describe the aim of the study 
- State the necessity of using animals for the study with consideration of alternatives

- Describe the outcomes of the study.

A proposal was sent to a number of AECs in New Zealand for comment (the authors are not aware of a similar survey in Australia). Of the 34 who responded, 21 were not supportive, four had reservations, and nine were supportive. Concerns raised included, intellectual property, confidentiality, and the cost of compliance. Some respondents thought lay summaries would provide ammunition for animal activists. It was also not unexpected that those engaged in "low impact" animal research were, in general, more in favor of the summaries.

A large section of the public does not feel well informed about animal research (Clemence and Leaman, 2016; Humane Research Australia, 2016a). Citizens are divided over animal research (Funk and Rainie, 2015; Jones, 2017) and want more transparency (Ärzte gegen Tierversuche, n.d.). As we have argued, increased transparency is needed as part of good governance and accountability. In the following, we propose steps to reform the current system.

\subsection{A Register of All Publicly Funded Animal Research Projects}

A recent report by the United Nations Secretary-General's High-Level Panel on Access to Medicines called for governments to require, "the unidentified data on all completed and discontinued clinical trials be made publicly available in an easily searchable public register" (United Nations, 2016, p. 37), including study designs and protocols, data sets, test results, and anonymity-protected patient data. The current lack of transparency of clinical trials, it is argued, undermines the ability of clinicians, researchers, and patients to make informed decisions about treatments. We argue that the same applies to animal research. To minimize publication and selective reporting biases (Ioannidis, 2012) and to improve accountability to the public, the quality of research, and the effectiveness and safety of new drugs and other treatments, raw data and full protocols of research projects using animals have to be made publicly available before the research starts. A first initiative is taken by the website PreclinicalTrials .org which provides an international online platform to register protocols for preclinical animal studies (PreclinicalTrials, n.d.). The preregistration of 
animal studies would also allow experts to advise on available non-animal methods. On completion of the research, we need to know what the research has contributed, and how that is balanced with the suffering of the animals used (Knight, 2011; Lund, Lassen and Sandoe, 2012; Lund et al., 2014). The NTS, as they currently exist in the $\mathrm{EU}$, will not deal with the problem of duplicated research and the unnecessary use of animals because they provide only limited information.

\subsection{Cost-benefit Analysis}

A cost-benefit analysis underpins animal research regulation in most countries. For example, Directive 2010/63/EU on the protection of animals used for scientific purposes (European Parliament, 2010) requires that the likely harm to an animal should be balanced against the expected benefits of the project. A similar, but considerably weaker, criterion appears in the Australian Code, stipulating that the potential effects on the well-being of animals involved in a project be justified by the potential benefits for humans, animals, or the environment.

Proponents of animal research claim that research involving animals has contributed to human clinical knowledge, but there are few systematic reviews of human clinical utility. Those that do exist show poor human utility of animal models for toxicity testing and the development of clinical interventions (Knight, 2011; see also Archibald, Coleman and Drake, 2019, Chapter 18; Greek and Kramer, 2019, Chapter 17; Knight, 2019, Chapter 14; and Ram, 2019, Chapter 15 in this Volume). Scant research exists on how the public views the tension between animal costs and human benefits. A group of researchers in Denmark (Lund et al., 2014) explored this topic in focus groups and an online survey. They found that respondents used cost-benefit approaches in their reasoning, even those who strongly supported or rejected animal research. Animal pain and research purpose were of greater importance in balancing the costs and benefits than the species of the animals. At present, researchers may inform us about the potential benefits of animal research projects; but we need more, as Knight (2011) argues: "To assess the degree to which experimental objectives were successfully met, the costs incurred by research animals, and to inform future research strategy and further experimental licensing decisions, retrospective evaluation of experiments should be mandatory where such experiments are considered likely to result in significant costs to laboratory animals or to public finances, or significant human benefits" (p. 293).

The harm-benefit calculation is at the heart of the ethical assessment of animal research. In the UK, it is conducted by the Home Office when researchers apply for a project license. In Australia, the animal ethics committee makes the determination. In both jurisdictions, there is very little evidence that any 
research proposal fails to pass ethical assessment; the purported benefits are always judged to outweigh the costs to the animals (Pound and Blaug, 2016; Russell, 2012). In the UK, there is a detailed description of the methodology used to calculate costs and benefits. The Australian states have similar, though less comprehensive, guides. In both cases, there is fudging on the crucial question of how to weigh or balance harms against costs. The Home Office guide, for example, considers the process as ultimately a value-laden judgment and often subjective. In neither instance can the completed cost-benefit assessments of the Animals in Science Regulation Unit (UK) and the AEC (Australia) be viewed by the public.

\subsection{Ethical Reproducibility}

Although researchers and animal ethics committees are directed to balance the likely harm to the animals against the expected benefits of the project, the public does not know how, or even whether, this occurs. Anderson et al. (2013) pointed out that descriptions of research ethics methods in published papers are minimally informative, and authors are not required to publish them. They suggest that ethical reproducibility requires reporting the concrete features of study design that deal with the specific ethical challenges of a research study. They propose the following guidelines for reporting:

- Report strategies used to avoid or replace the use of animals in research that has the potential to cause them harm

- Report improvements to procedures and husbandry that minimize actual or potential pain, suffering, distress, or lasting harm and/or improve animal welfare in situations in which the use of animals is unavoidable

- Report methods that minimize animal use and enable researchers to obtain comparable levels of information from fewer animals.

Furthermore, Anderson et al. (2013) argue that ethics reporting should be guided by the principles of transparency (i.e., reporting sufficient detail to enable readers to assess and reproduce the research ethics methods used) and proportionality (i.e., providing detail at a level that is proportionate to the ethical complexity and risk to animals).

\subsection{Development of Non-animal Methods and Training}

If they are serious about the implementation of the ${ }_{3} \mathrm{Rs}$, government funding bodies need to provide support and dedicated resources for the development of non-animal methods, and researchers need training in up-to-date non-animal methods (see Herrmann, 2019 Chapter 1 in this Volume). In Australia, the government body that funds biomedical research, the NHMRC, does not dedicate funding, specifically, to the development of animal-free research methods. 


\subsection{Additional Considerations for Australia}

In Australia, animal experimenters, their institutions, and federal and state/ territory governments provide far less information of interest to the public about animal research than in EU countries. As a first step, we propose that already existing information be made publicly available, without identifying details. This would include the records of AEC meetings; AEC annual reports to their institutions; licensed institutions' annual reports to their state/territory government; and institutions' reports of AEC external reviews, which are, according to the Code, to be undertaken at least every four years. Monitoring the care and use of animals is one of the responsibilities of the AECs. According to the Code, it is left to them to determine the timing and frequency of inspections. Facility inspections may also be undertaken by state governments. Again, reports about facility inspections exist but the information is not publicly available.

Furthermore, the NHMRC, as the largest funding-body of biomedical research, is the appropriate organization to make the details of funded animal research available. The NHMRC already provides lists of funded projects (NHM$\mathrm{RC}, 2018)$. However, from the project descriptions in these lists, it is unclear whether the research uses animals. It should be easy to add this detail. The next step would involve achieving consistency of reporting. An independent animal welfare office at the federal level would be suitable to take on this task. However, so far, Australia does not have such an independent organization. Consistency of reporting would involve consistent categories across all states/ territories for animal species, purposes of use, and severity of procedures (Bain and Debono, 2013).

Transparent reporting as part of the research community's accountability to the public and funders requires additional information. Hadley (2012) notes that animal use data are collected by researchers and intended for the public record but are rarely given meaningful media exposure. Hadley suggests that animal researchers provide concise summaries of their projects to journalists and public relations practitioners. We propose that Australia develops a practice similar to the one implemented in the EU, where non-technical, plain language summaries are published online and accessible to the public. We suggest these summaries clearly describe what happens to animals undergoing procedures in a way that the public can understand. This type of openness would provide the public with a more impartial way to evaluate the animals' experiences against the intended benefits of the research conducted upon them.

Bain and Debono call for a "national statistics compilation that systematically reports on the degree of ${ }_{3}$ Rs implementation" (2013, p. 215). Given that the ${ }_{3}$ Rs are central to the Code, and AECs are already asking a number of questions 
regarding the implementation of the $3 \mathrm{Rs}$, such a compilation would contribute to accountability and transparency of animal research. Furthermore, it would provide benchmark information on how patterns of animal use are changing over time. At present, scant information is provided about the living environments of animals in laboratories, such as enrichment, opportunities to express species-specific behaviors, and whether individual animals are kept in isolation from other animals. This is of interest to the public and could be provided on a website, as some research institutions in the EU already do. Transparency is central to the scientific method and ethical conduct. We trust that genuine transparency will lead to greater scrutiny of animal research projects, which in turn will lead to greater reduction and replacement of animals in research.

\section{5}

\section{Conclusion}

It is argued, at times, that greater transparency can help the cause of both sides of the animal research debate (Hadley, 2012; O'Sullivan, 2006). Critics have also sought more information to expose the injustice of what is done to animals in the laboratory. On the other side, initiatives such as the Concordat (UK) and the NTS (EU) are viewed by at least some in the research community as opportunities to show the importance of their work and to counter the claims of animal advocates. On balance, though, critics more urgently demand openness than users. Those engaged in animal experimentation do so legally and do not have to convince regulators or funders that they are not doing anything wrong. To deal with public opinion, the default strategy in many countries, including Australia, has been to keep the public largely ignorant.

To date, improved transparency, since the introduction of Directive $2010 / 63 / \mathrm{EU}$, has not yet led to better implementation of the 3 Rs; and, overall, the number of animals used in research has not decreased. We hope, nonetheless, that more openness will be seen in Europe, spread to other countries, and lead to a paradigm change. If this comes about, the public will see:

- More disclosure of impacts, pain, deaths, and fate of animals (in particular, information about the levels of impact by research purpose)

- More unnecessary studies revealed, such as duplicated research, studies for which non-animal alternatives are available, or studies that are trivial and should not have been undertaken

- More clues regarding trends, such as the use of donated greyhounds, increasing use of transgenic animals, including non-human primates, or xenotransplantation

- Information on return on investment and transferability of results to humans. 
At Humane Research Australia, we are convinced that when this kind of information is revealed, public opinion will swing against animal experimentation. There is also no doubt that we would use such data to continue our advocacy for more ethical and human-relevant research.

\section{References}

Anderson, J.A., M. Eijkholt and J. Illes (2013). Ethical Reproducibility: Towards Transparent Reporting in Biomedical Research. Natural Methods, 10(9), pp. 843-845.

Archibald, K., R. Coleman and T. Drake (2019). Replacing animal tests to improve safety for humans. In: K. Herrmann and K. Jayne, eds., Animal Experimentation: Working Towards a Paradigm Change, Vol. 22. Brill Human Animal Studies Series, pp. 417442. Leiden: Brill.

Ärzte gegen Tierversuche (n.d.). Europas Bürger wollen keine grausamen Tierversuche. Umfrage zu Tierversuchen in sechs EU-Ländern. [online] Available at: https://www .aerzte-gegen-tierversuche.de/de/infos/statistiken/259-europas-buerger-wollenkeine-grausamen-tierversuche [Accessed 17 September 2016].

Australian and New Zealand Council for the Care of Animals in Research and Teaching (2007). Recent Actions Arising from the 2003 ANZCCART Conference. ANZCCART Working Party. Australian and New Zealand Councilfor the Care of Animals in Research and Teaching News, 20(2), pp. 5-6.

Bain, S. and K. Debono (2013). Australian Scientific Animal Use Statistics: A History of Fragmentation, a Future of Hope. Proceedings of the 2013 ANZCCART Conference “Can We Do Better?". Sydney: Australian and New Zealand Council for the Care of Animals in Research and Teaching Ltd. (ANZCCART). [online] Available at: https:// www.adelaide.edu.au/ANZCCART/publications/proceedings/2013proceedings.pdf [Accessed 5 May 2017].

Basel Declaration (2011). Basel Declaration. [online] Available at: http://www.baseldeclaration.org/basel-declaration/ [Accessed 11 August 2018].

Clemence, M. and J. Leaman (2016). Public Attitudes to Animal Research in 2016. [online] Available at: https://www.ipsos.com/sites/default/files/publication/1970-o1/ sri-public-attitudes-to-animal-research-2016.pdf [Accessed 5 May 2017].

European Parliament (2010). Directive 2010/63/EU of the European Parliament and of the Council of 22 September 2010 on the Protection of Animals Used for Scientific Purposes. Official Journal of the European Communities, L276, p. 33-79. Available at: http://eur-lex.europa.eu/legal-content/EN/TXT/?uri=CELEX:32010Loo63 [Accessed 5 May 2017].

European Union (2016). Transparency Register. Transparency and the EU. [online] Available at: http://ec.europa.eu/transparencyregister/public/homePage.do [Accessed 11 October 2016]. 
Funk, C. and L. Rainie (2015). Public and Scientists' Views on Science and Society. [online] Available at: http://www.pewinternet.org/2015/01/29/public-and-scientistsviews-on-science-and-society/ [Accessed 5 May 2017].

Freedom of Information Act 1982. Version incorporating amendments as at 1 September 2017. State Government of Victoria, 2018. [online] Available at: http://www .legislation.vic.gov.au/domino/Web_Notes/LDMS/LTObject_Store/ltobjstio.nsf/ DDE30oB846EED9C 7 CA257616oooA3571/DD1AE7Bo876CA9B9CA25818Dooo8F 72D/\$FILE/82-9859aa100\%20authorised.pdf [Accessed 10 August 2018].

Greek, R. and L.A. Kramer (2019). The scientific problems with using non-human animals to predict human response to drugs and disease. In: K. Herrmann and K. Jayne, eds., Animal Experimentation: Working Towards a Paradigm Change, Vol. 22. Brill Human Animal Studies Series, pp. 391-416. Leiden: Brill.

Hadley, J. (2012). Telling It Like It Is: A Proposal to Improve Transparency in Biomedical Research. Between the Species, 15(1), 0021.

Herrmann, K. (2019). Refinement on the way towards Replacement: Are we doing what we can? In: K. Herrmann and K. Jayne, eds., Animal Experimentation: Working Towards a Paradigm Change, Vol. 22. Brill Human Animal Studies Series, pp. 3-64. Leiden: Brill.

Holmberg, T. and M. Ideland (2012). Secrets and Lies: "Selective Openness" in the Apparatus of Animal Experimentation. Public Understanding of Science, 21(3), pp. 354-368.

Home Office Department for Business Innovation and Skills and Department of Health (2015). Working to Reduce the Use of Animals in Scientific Research. Delivery Report. [online] Available at: https://www.gov.uk/government/uploads/system/ uploads/attachment_data/file/417441/Delivery_Report_2015.pdf [Accessed 5 May 2017].

Humane Research Australia (2016a). Australians Say No to Animal Experiments. [online] Available at: http://www.humaneresearch.org.au/interview/australians-sayno-to-animal-experiments [Accessed 11 November 2017].

Humane Research Australia (2016b). Statistics of Animal Use in Research and Teaching in Australia. [online] Available at: http://www.humaneresearch.org.au/statistics/ [Accessed 5 August 2018].

Humane Research Australia (2016c). 2016 Australian Statistics of Animal Use in Research \& Teaching. [online] Available at: http://www.humaneresearch.org.au/ statistics/statistics_2016 [Accessed 11 August 2018].

Ioannidis, J.P.A. (2012). Extrapolating from Animals to Humans. Science Translational Medicine, 4(151), pp. 1-4.

Ipsos, MORI (2013). Openness in Animal Research. The Public's Views on Openness and Transparency in Animal Research. [online] Available at: https://www.ipsos. com/sites/default/files/publication/1970-01/sri-health-openness-in-animalresearch-2013.pdf [Accessed 5 May 2017]. 
Jones, J.M. (2017). Americans Hold Record Liberal Views on Most Moral Issues. Gallup Poll. [online] Available at: http://www.gallup.com/poll/210542/americans-holdrecord-liberal-views-moral-issues.aspx [Accessed 25 August 2017].

Knight, A. (2011). Weighing the Costs and Benefits of Animal Experiments. Alternatives to Animal Experimentation Proceedings, Eighth World Congress on Alternatives and Animal Use in the Life Sciences (WC8). Montreal, Canada. [online] Available at: http://www.altex.ch/resources/289294_Knight131.pdf [Accessed 5 May 2017].

Knight, A. (2019). Critically evaluating animal research. In: K. Herrmann and K. Jayne, eds., Animal Experimentation: Working Towards a Paradigm Change, Vol. 22. Brill Human Animal Studies Series, pp. 321-340. Leiden: Brill.

Lund, T.B., J. Lassen and P. Sandoe (2012). Public Attitude Formation Regarding Animal Research. Anthrozoos: A Multidisciplinary Journal of The Interactions of People \& Animals, 25(4), pp. 475-490.

Lund, T.B., M.R. Mørkbak, J. Lassen and P. Sandøe (2014). Painful Dilemmas: A Study of the Way the Public's Assessment of Animal Research Balances Costs to Animals Against Human Benefits. Public Understanding of Science, 23(4), pp. 428-444.

McLeod, C. and P. Hobson-West (2015). Opening Up Animal Research and Science Society Relations? A Thematic Analysis of Transparency Discourses in the United Kingdom. Public Understanding of Science, 25(7), pp. 791-8o6.

National Health and Medical Research Council (2013). Australian Code for the Care and Use of Animals for Scientific Purposes. 8th Edition. Canberra. [online] Available at: http://www.nhmrc.gov.au/guidelines/publications/ea28 [Accessed 5 May 2017].

National Health and Medical Research Council (2018). Outcomes of Funding Rounds. [online] Available at: https://www.nhmrc.gov.au/grants-funding/outcomes-funding -rounds [Accessed 23 January 2018].

O'Sullivan, S. (2006). Transparency and Animal Research Regulation: An Australian Case Study. Animal Liberation Philosophy and Policy Journal, 4(1).

Pound, P. and R. Blaug (2016). Transparency and Public Involvement in Animal Research. Alternatives to Laboratory Animals, 44(2), pp. 167-173.

PreclinicalTrials (n.d.). About PreclinicalTrials.eu. [online] Available at: https://www .preclinicaltrials.eu/\#aboutSitePage [Accessed 11 August 2018].

Queensland Government Department of Agriculture and Fisheries (2014). Public Access to the Register of Scientific Animal Use. [online] Available at: https://www .daf.qld.gov.au/animal-industries/welfare-and-ethics/using-animals-for-scientificpurposes/registering-as-an-animal-user/public-access-to-the-register [Accessed 14 October 2016].

Ram, R. (2019). Extrapolation of animal research data to humans: an analysis of the evidence. In: K. Herrmann and K. Jayne, eds., Animal Experimentation: Working Towards a Paradigm Change, Vol. 22. Brill Human Animal Studies Series, pp. 341-375. Leiden: Brill. 
Russell, D. (2012). Why Animal Ethics Committees Don't Work. Between the Species, 15(1).

Tasmanian Government, Department of Primary Industries Parks Water and Environment (2017). Animal Research Statistics Tasmania. Annual Report 21 (2016). Hobart. [online] Available at: http://dpipwe.tas.gov.au/Documents/Animal\% 2oResearch\%2oStatistics\%2oTasmania\%2oAnnual\%2oReport\%2021.pdf [Accessed 11 August 2018].

Understanding Animal Research (n.d.). Concordat on Openness on Animal Research. [online] Available at: http://concordatopenness.org.uk/ [Accessed 12 August 2018]. United Nations (2016). Report of the United Nations Secretary-General's High-Level Panel on Access to Medicines. Promoting Innovation and Access to Health Technologies. [online] Available at: http://www.politico.eu/wp-content/uploads/2016/og/HLPReport-FINAL-Sept-2016.pdf [Accessed 11 August 2018].

University of Cambridge (2018). University Biomedical Services. Animal Welfare and Ethical Review Body Redacted Committee Minutes. [online] Available at: https://www .ubs.admin.cam.ac.uk/animal-welfare-ethical-review-body/redacted-committeeminutes [Accessed 1 February 2018].

University of Melbourne (n.d.). Forms and templates. [online] Available at: https:// staff.unimelb.edu.au/research/ethics-integrity/animal-ethics/forms-guidanceand-training/forms-and-templates [Accessed 10 August 2018].

University of Nottingham (n.d.). Animal Research at Nottingham. Minutes of Animal Welfare and Ethical Review Body Meetings. [online] Available at: https://www .nottingham.ac.uk/animalresearch/awerb/minutes-of-awerb-meetings.aspx [Accessed 1 February 2018].

Varga, O., A.K. Hansen, P. Sandøe and I.A.S. Olsson (2010). Improving Transparency and Ethical Accountability in Animal Studies. Three Ways to link Ethical Approvals to Publications. European Molecular Biology Organization reports, 11(7), pp. 500-503.

Whittaker, A. (2014). Animal Research Regulation in Australia-Does It Pass the Test of Robustness? Global Journal of Animal Law, 1.

Williams, A.J. (2015). Concordat on Openness on Animal Research in the UK. Annual Report 2015. [online] Available at: http://www.understandinganimalresearch.org.uk/ files/9214/4319/6363/UAR_Concordat_Report_2015.pdf [Accessed 5 October 2016].

Williams, A.J. (2017). Concordat on Openness on Animal Research in the UK. Annual Report 2017. London. [online] Available at: http://concordatopenness.org.uk/wpcontent/uploads/2017/12/Concordat-Report-2017.pdf [Accessed 1 February 2018].

Yeates, J.W. and B. Reed (2015). Animal Research Through a Lens: Transparency on Animal Research. Journal of Medical Ethics, 41(7), pp. 504-505. 